\title{
A Simulation Study on Performance Improvement of Solar Assisted Heat Pump Hot Water System by Novel Controllable Crystallisation of Supercooled PCMs
}

\author{
Cagri Kutlu ${ }^{* 1}$, Yanan Zhang ${ }^{1}$, Theo Elmer ${ }^{2}$, Yuehong Su ${ }^{1}$, Saffa Riffat $^{1}$ \\ ${ }^{I}$ Department of Architecture and Built Environment, Faculty of Engineering, University of \\ Nottingham, University Park, Nottingham NG7 2RD, UK \\ ${ }^{2}$ Geo Green Power Ltd. Green Barn Costock Road, NG12 5QT, Nottingham, UK
}

Domestic hot water (DHW) has a significant share in building's energy consumption. In order to reduce this consumption, various solutions have been proposed such as controlling the system in an efficient way, using renewable sources and using phase change materials (PCM) in the system to increase heat capacity. However, this study is not only offering heat capacity improvement of the DHW storage unit but also proposing that energy efficiency can be improved by controlling the heat releasing time of the PCM. In this study, supercooled PCM tubes are placed in a water tank and charged with a solar assisted heat pump unit, these supercooled PCM tubes can then be discharged anytime when the hot water is required. In this paper, a transient thermodynamic model is built for the whole system including solar collector, heat pump, water tank with PCM and DHW demand profile. System components are modelled and a 24 hours of demand profile is used in simulation for a UK home for summer and spring weather conditions. The results show that the PCM tubes effectively compensate the morning peak hot water demand and reduce daily energy consumption around $12.1 \%$ and $13.5 \%$ by shifting heating provision from immersion heater to solar heat pump.

Keywords: Supercooled PCM, Solar assisted heat pump, DHW, Transient thermodynamic simulation 


$\begin{array}{cl}A_{c o l} & \text { Collector area, } \mathrm{m}^{2} \\ c_{1} & \text { Heat loss term, } \mathrm{W} \mathrm{m}^{-2} \mathrm{~K}^{-1} \\ c_{2} & \text { Heat loss term, } \mathrm{W} \mathrm{m}^{-2} \mathrm{~K}^{-2} \\ c_{p} & \text { Specific heat, } \mathrm{Jg}^{-1} \mathrm{~K}^{-1} \\ D & \text { Diameter, } \mathrm{m} \\ G & \text { Solar irradiance, } \mathrm{W} \mathrm{m}{ }^{-2} \\ h & \text { Specific enthalpy, } \mathrm{J} / \mathrm{kg} \\ h_{w-P C M} & \text { Heat transfer coefficient, } \mathrm{W} \mathrm{m}{ }^{-2} \mathrm{~K}^{-1} \\ H & \text { height of the water element, } \mathrm{m}^{-1} \\ \dot{m} & \text { Mass flow rate, } \mathrm{kg} \mathrm{s}{ }^{-1} \\ M & \text { Mass, kg } \\ \mathrm{Nu} & \text { Nusselt number } \\ \mathrm{Pr} & \text { Prandtl number } \\ \mathrm{Ra} & \text { Rayleigh number } \\ \dot{Q} & \text { Heat flow rate, } \mathrm{W} \\ T & \text { Temperature, }{ }^{\circ} \mathrm{C} \\ \bar{T} & \text { Mean temperature in collector, }{ }^{\circ} \mathrm{C} \\ U & \text { Overall heat transfer coefficient, } \mathrm{W} \mathrm{m}^{-2} \mathrm{~K}^{-1} \\ \mathrm{~V} & \text { Volume, }{ }^{3}\end{array}$

\section{Greek letters}

$\begin{array}{cl}\varepsilon & \text { Effectiveness } \\ \eta & \text { Efficiency } \\ \rho & \text { Density, } \mathrm{kg} \mathrm{m}^{-3} \\ \phi & \text { PCM liquid fraction } \\ \lambda_{\text {eff }} & \text { vertical effective thermal } \\ & \text { conductivity, } \mathrm{W} \mathrm{m}^{-1} \mathrm{~K}^{-1}\end{array}$

\section{Subscripts}

$\begin{array}{cl}\text { am } & \text { Ambient } \\ \text { col } & \text { Collector } \\ \text { cond } & \text { Condenser } \\ \text { DHW } & \text { Domestic hot water } \\ \mathrm{e} & \text { Evaporator } \\ \mathrm{htf} & \text { Heat transfer fluid } \\ \mathrm{n} & \text { Node number } \\ \text { in } & \text { Inlet } \\ \text { out } & \text { Outlet } \\ r & \text { Refrigerant } \\ \mathrm{SH} & \text { Super heating } \\ s t & \text { Storage } \\ t & \text { Tank } \\ w & \text { Water }\end{array}$




\section{Introduction}

About $30 \%$ of UK energy usage is consumed by buildings, $50-60 \%$ of this energy usage is required for heating, ventilation and air conditioning (HVAC) systems[1]. This figure is consistent throughout the worldwide. In the UK, heating and hot water make up $40 \%$ of building energy use and $20 \%$ of associated greenhouse gas emissions [2]. These emissions must be reduced by over $20 \%$ by 2030 , with a near complete decarbonisation by 2050 , as part of the legally binding targets set by Parliament in the Climate Change Act. To reach these targets, new, highly efficient renewable heating systems must be developed to meet heating demand in a sustainable and economic manner. Thus, this paper aims to offer an energy efficient solution for DHW consumption in houses by using a novel control method of a heat storage material by a sustainable way.

As it is known, heat pumps can be used as a viable alternative to electric heaters and boilers in DHW applications in order to reduce energy consumption and carbon release rates. Heat pump technology which is an attractive option because of its low electricity consumption [3]. Moreover, it has capability to utilize renewable energy like solar, which can serve as an ideal heat/electrical source for the heat pump unit. It has been proven that a solar assisted heat pump (SAHP) system can effectively cut electricity consumption and improve the renewable energy utilisation for domestic heating [4]. As solar energy can be used to drive heat pump's compressor by PV electricity or it can be coupled with ground source or air source heat exchangers to improve performance, it is reported that solar thermal heat pump is the mostly studied and cost effective one [5]. There are also promising results have been published for SAHPs' good performance under cold winter conditions. Kong et al [6] experimentally tested a direct expansion SAHP unit during autumn and winter period and reported COP was higher than 4 in autumn and higher than 2.5 in winter. Recently, Yardesh et al. [7] presented that two stage cascade SAHP unit can provide sufficient heating even for very cold climate regions. A SAHP unit is adapted for the proposed DHW system in this paper.

Heat storage units in DHW applications are generally achieved by sensible heating of a tank because the units are commonly used to supply instant hot water. Thus, the amount of stored heat depends on the heat capacity of the storage, which is related to the volume. Phase change materials (PCM) can be a solution of this volume issue because PCMs can store sensible and latent heat in DHW applications which can result in a smaller volume for the same heat capacity storage. Moreover, DHW energy consumption reaches about $19 \%$ of the total energy consumption of a UK dwelling. In order to decrease this consumption, PCM usage in the system is a promising alternative because PCMs have the characteristic of high energy density, which is used as an energy storage media in latent thermal energy storage units when heat is available or cheaper to produce.

To realise the benefits of PCM usage in DHW systems, many researchers have built models and carried out testing. These studies mainly focus on the various types of PCM properties and configurations within a water tank. Mehling et al.[8] prepared an experiment and presented that adding PCM at the top of water tank increases storage capacity and compensate heat losses. Talmatsky and Kribus [9] conducted a modelling study of PCM with water storage and analysed the performance considering the domestic hot water demand. They concluded that using PCM has no significant energy efficiency advantage for end users, and they explained that reheating of the water by the PCM during night time is responsible 
for increased losses to the environment. Kousksou et al. [10] considered the same mathematical model with Talmatsky [9] and prepared a water tank model included solar collectors, PCM and auxiliary heater. They described that energy efficiency is highly sensitive to the selected PCM melting temperature, so the design parameters should be analysed carefully. Padovan and Marzan [11] reported that optimization is very important; thus, they proposed a generic algorithm optimization to evaluate sensitivity of the parameters, such as tank geometry and PCM melting temperatures. Kumar et al. [12] prepared an experiment to test the effect of water flow rate and inlet temperature of the heat transfer fluid into the water tank with PCM. They concluded that the addition of PCM capsules can increase the stratification level of the water tank which is a useful parameter for heat storage applications. Finally, Shirinbakhsh et al. [13] comprehensively analysed the effect of DHW demand on performance of solar domestic hot water systems. They concluded that embedding PCMs in the storage tanks is not a promising solution and performance is dependent up on the operating conditions. Therefore, they recommended that the DHW demand profile should be taken into consideration.

It can be seen that a unanimous conclusion has not yet been reached regarding PCM use in DHW systems. This is because many influential parameters exist in the type of system. Researchers agreed that optimisation is important to realise the benefits from PCM. In contrary, the study presented in this paper proposes the use of supercooled PCMs. A supersaturated solution is a solution with more dissolved solute than the solvent would normally dissolve in its normal conditions. Supersaturation is achieved by dissolving a solute in one set of conditions, then transferring it to another condition without triggering any release of the solute [14]. Supersaturated solutions are extremely unstable, but often require a triggering event to begin returning to the stable state via the solute coming out of solution. Supersaturated solutions will also undergo crystallization under specific conditions [15]. In a normal solution, once the maximum amount of solute is dissolved, adding more solute would cause the dissolved solute to precipitate out [16]. In the supersaturated condition, the solute will simply precipitate out by a small activation in the solution. It is because supersaturated solution is in a very high energy state and crystallization can occur by releasing energy. The solution will then move to a lower energy state. The activation energy comes in the form of a nuclei crystal being added to the liquid solution. This nuclei can be either added from an external source or from within the solution due to ion and molecule interactions [17]. Most of the PCM supersaturated solutions are not steady. Canbazoğlu et al. [18] studied sodium thiosulfate as a thermal heat storage material. They reported that a sodium thiosulfate supersaturated solution can be activated easily by small vibration or heat. Nucleation inhibitors such as Sodium Alginate should be added in the solution to control the formation of crystals. Without a nucleation inhibitor, crystals can be formed in the PCM supersaturated solution with a little vibration. Thus, sodium acetate was selected as the thermal storage materials in this study because of its relative steady state at supercooled condition and the suitable melting temperature of $58{ }^{\circ} \mathrm{C}$, which can provide promising hot water supply for houses. Moreover, Sodium acetate is widely used in food additives, so it is a relatively safe material among PCMs [19]. Supercooled sodium sodium acetate solution is commonly used as reusable gel heating pads (hand warmer). A hand warmer contains a supersaturated solution of sodium acetate which releases heat upon crystallization. This solution is capable of cooling to room temperature without forming crystals [20]. Pressing on a small mechanical "clicker" within the heating pad activates the nucleation centres and starts the reaction, a 
nucleation centre is formed, causing the solution to crystallize back into solid sodium acetate trihydrate. In order to activate this supercooled PCM for heat releasing, some controllable triggering methods, i.e., applying electric field and mechanical release of nucleating agents have been proposed by several authors [21], [22], [23].

Therefore, this study differs from the literature by using a novel supercooled PCM and the controlling methodology. To show the performance improvement level in a realistic environment, solar collector, heat pump, water tank and hot water demand profile are comprehensively modelled in a transient state. Performance of conventional and PCM enhanced tanks in DHW systems are compared. Heat pump performances, energy consumption profiles and temperature gradients in the tank during a day are given. The objectives of the study are summarized below:

- In order to reduce energy consumption in DHW applications, supercooled PCMs and a novel operation controlling methodology are presented.

- To operate the systems in more sustainable way, the solar assisted heat pump units are implemented in the study.

- To show effect of the using supercooled PCM and its new control methodology, performances of the SAHP units with conventional tank and PCM enhanced tank are analysed and compared.

- Performances of the systems for specified days in summer and spring are compared and discussed.

\section{System description and methodology}

The proposed system mainly aims to use supercooled PCM tubes inside the water tank to improve heating capacity and especially increase the energy efficiency of the system. Therefore, cylindrical PCM tubes are in the water tank as seen in Fig. 1. PCMs are placed to the top part of the tank to benefit from thermocline behaviour of the water tank.

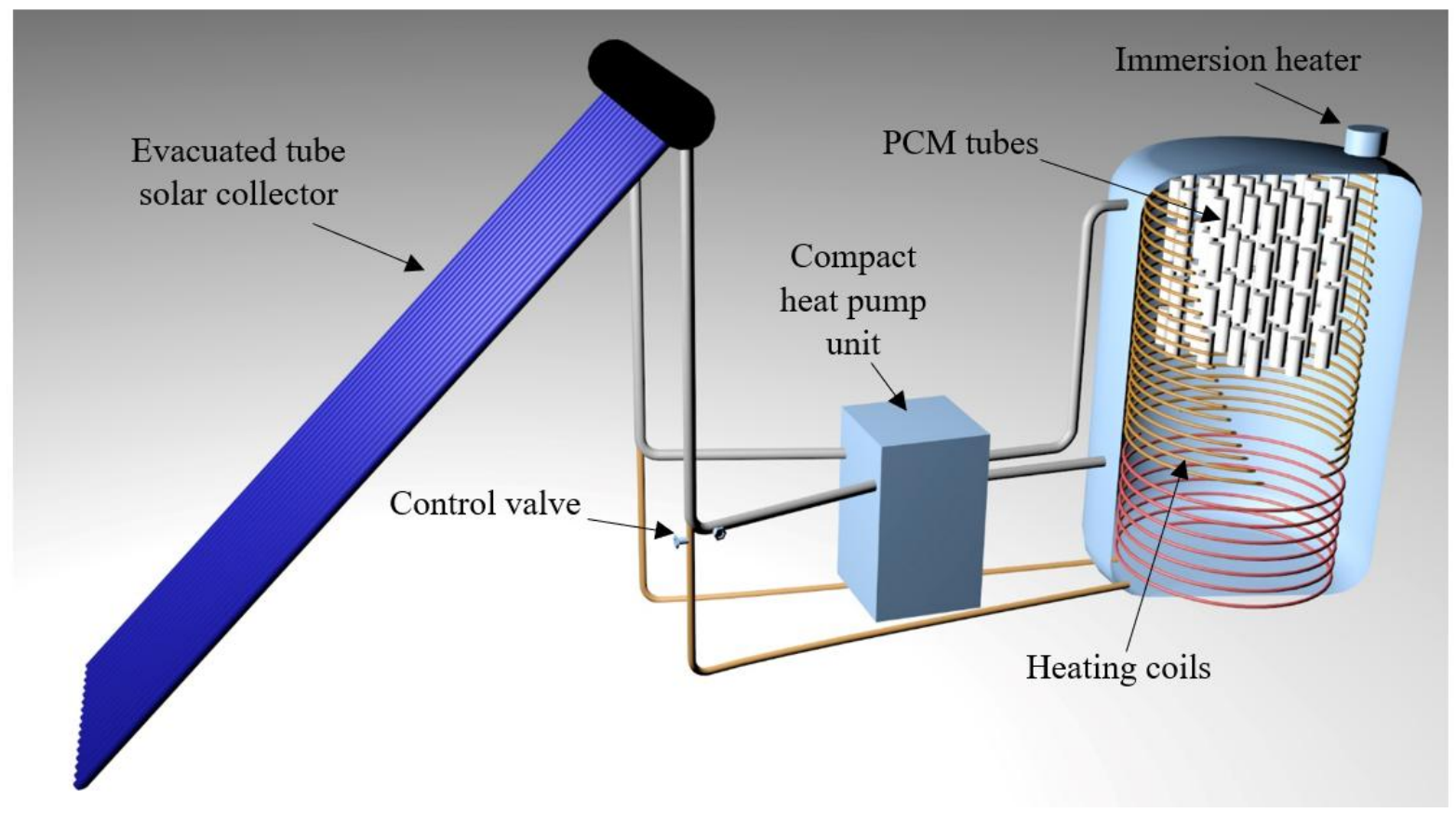


Fig.1. Solar assisted heat pump hot water system with a PCM integrated water tank The system's operation modes are given in Fig. 2. The solar assisted heat pump system consists of four subsystems. The first subsystem is solar collector. Evacuated tube heat pipe collectors are selected for heating the circulating water because these collectors show very good performance even under low ambient temperature conditions. Heated water by the collector is used as a heat source for heat pump unit or for heating coil in the water tank depending on the operating mode. The second subsystem is heat pump device. It is a water source heat pump unit which boosts the collected heat from the solar collector and increases the tank temperature until top temperature reaches to a desired level. As a third subsystem, water tank is used, which is common in dwellings. The water tank stores heat to provide hot water to the residents. Finally, transient domestic load profile is modelled to test system's performance under real conditions.

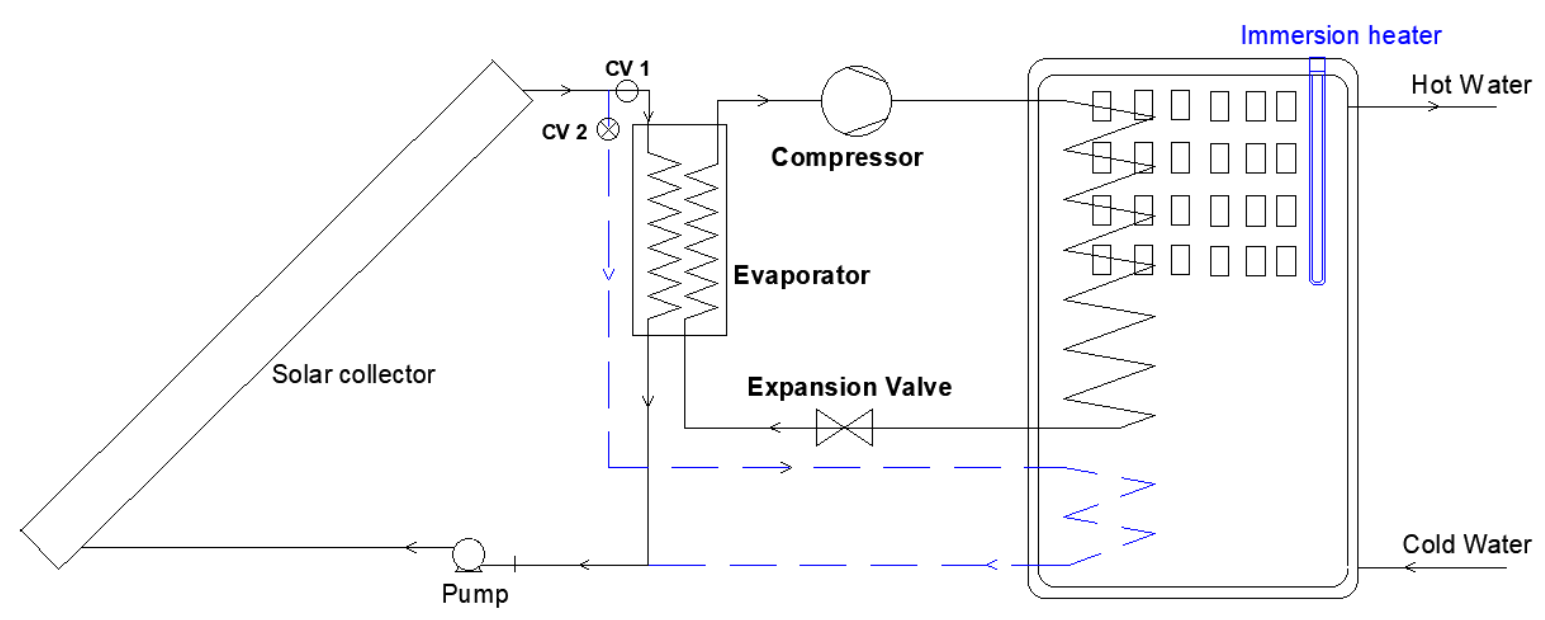

a) Heat pump in operation

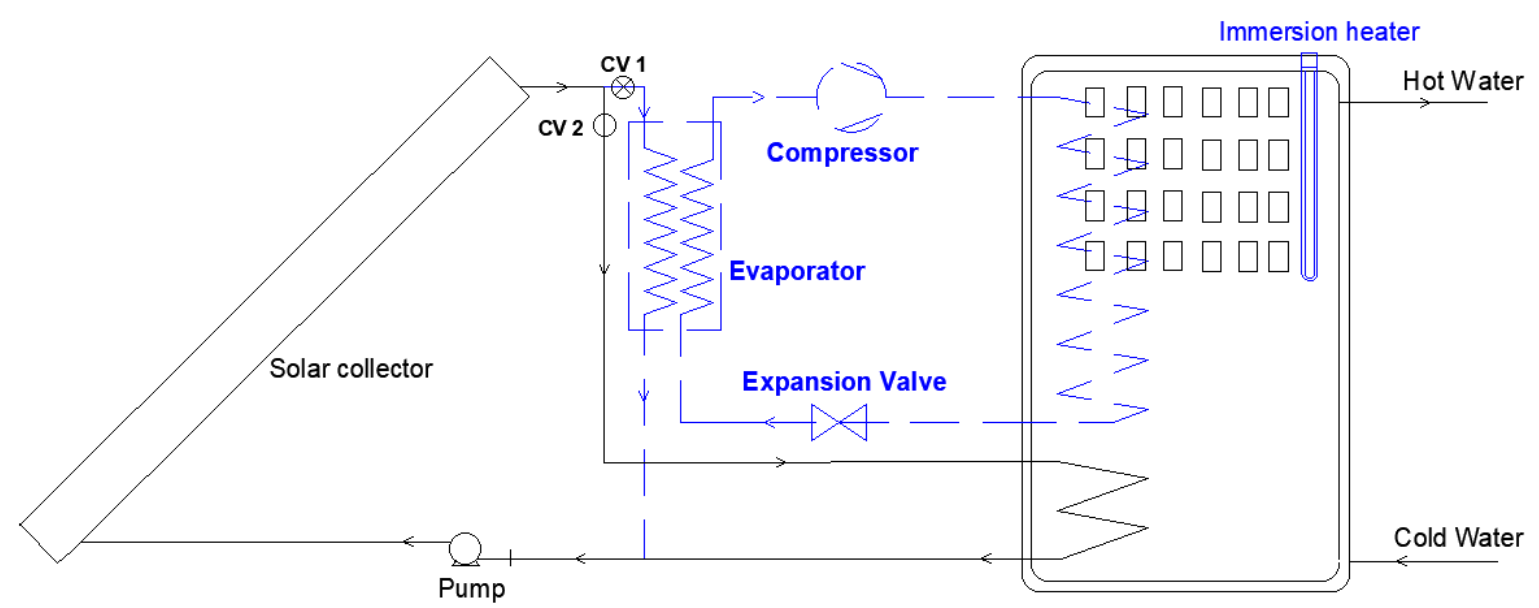

b) Direct solar heating

Fig.2. Schematic of the solar assisted heat pump hot water system. a) Heat pump is active only, b) Direct solar heating only

To control the temperature in the water tank, the temperature of the first node of water is considered (as the tank model is multi node model). The set temperature is chosen as $70{ }^{\circ} \mathrm{C}$ to avoid legionella and to be sure about the PCM melting. When water temperature is lower than the set point, control valve 1 is opened and control valve 2 is closed. Thus, the heat 
pump boosts the water temperature until temperature of the first element reaches to the set point, as shown in Fig.2a, the blue and dashed lines show inactivity. When temperature reaches the set temperature, control valve 1 is closed and control valve 2 is opened, the heat pump is turned off and collected heat directly circulated in the smaller coil in the water tank, which is shown in Fig.2b. During the day time domestic water demand decreases the water temperature in the tank; however, system is not turned on until first node temperature falls to $65^{\circ} \mathrm{C}$.

\subsection{Enhancement of heat capacity of the water tank by PCMs}

Ideal water tank volume is related with domestic hot water consumption and solar collector area. It is recommended that relationship between tank volume and collector area for solar water heating systems is given as $0.05 \mathrm{~m} \leq \mathrm{V} / \mathrm{A} \leq 0.18 \mathrm{~m}$ [24]. However, this equation is suitable for direct solar heating systems in good solar regions. The UK suffers from low solar radiation and solar heaters need auxiliary heating equipment and larger collector areas. $4 \mathrm{~m}^{2}$ collector area is chosen. Selection of tank size is also important for energy efficient houses and some equations are available, which mostly depend on number of occupants living in the dwelling. Moreover, companies also suggest that the ideal tank size depends on occupant number, and the number of bedrooms etc. Popular tank sizes for the UK are $120 \mathrm{~L}, 150 \mathrm{~L}$ and $200 \mathrm{~L}$. In this study, an average family home is considered and a 150 litre tank is chosen for the analysis.

Selection for proper PCM in DHW applications have been studied by many researchers. As hot water demand temperature is around $60^{\circ} \mathrm{C}$, popular PCM materials for this application are generally chosen with a melting temperature of $40-60{ }^{\circ} \mathrm{C}$. In this study, sodium acetate trihydrate is chosen because its steady supercooling property and being relatively safer among the other PCMs. Thermophysical properties of the solution slightly change according to solution concentration and temperature [25]. In the simulation, melting temperature is assumed as $58^{\circ} \mathrm{C}$ and other properties are assumed as constant. The used thermophysical properties of supercooled sodium acetate solution are given in Table 1.

Table 1. Thermophysical properties of the sodium acetate trihydrate [26]

\begin{tabular}{|l|l|}
\hline Physical Property & Value \\
\hline Latent heat of fusion & $250 \mathrm{~kJ} / \mathrm{kg}$ \\
\hline Density & $1520 \mathrm{~kg} / \mathrm{m}^{3}$ \\
\hline Specific heat & $2.719 \mathrm{~kJ} /(\mathrm{kgK})$ \\
\hline Thermal conductivity & $0.8 \mathrm{~W} /(\mathrm{mK})$ \\
\hline
\end{tabular}

By using given properties in Table 1, enhancement of energy storage capacity in different volumetric proportions of the water and PCM in the tank can be found. Results are given in Table 2. When the tank temperature reduces from $70{ }^{\circ} \mathrm{C}$ to $40{ }^{\circ} \mathrm{C}$, energy storage capacities for different proportions of PCM replacement with water is shown. Stored energy between 70 ${ }^{\circ} \mathrm{C}-40{ }^{\circ} \mathrm{C}$ is $25.2 \mathrm{MJ}$ for 200 litre water, however, when $10 \%$ of the total volume is changed with the PCM, the total heat storage capacity for given temperatures reaches $32.76 \mathrm{MJ}$. 
Table 2. Energy storage capacities of DHW tank

\begin{tabular}{|c|c|c|c|c|c|c|c|}
\hline \multirow{2}{*}{$\begin{array}{c}200 \\
\text { tank }\end{array}$} & \multicolumn{3}{|c|}{ PCM } & \multicolumn{2}{c|}{ Water } & \multicolumn{2}{c|}{ Tank $\left(\mathbf{4 0}^{\circ} \mathrm{C}-\mathbf{7 0}^{\circ} \mathrm{C}\right)$} \\
\cline { 2 - 8 } & $\begin{array}{c}\text { Latent } \\
\text { heat }\end{array}$ & $\begin{array}{c}\text { Sensible } \\
\text { heat }\end{array}$ & $\begin{array}{c}\text { Mass } \\
(\mathbf{k g})\end{array}$ & $\begin{array}{c}\text { Sensible } \\
\text { heat }\end{array}$ & $\begin{array}{c}\text { Mass } \\
(\mathbf{k g})\end{array}$ & Storage capacity & $\begin{array}{c}\text { Mass } \\
(\mathbf{k g})\end{array}$ \\
\hline Water only & - & - & - & 25.2 & 200 & $25.2 \mathrm{MJ}$ & 200 \\
\hline $5 \%$ PCM & 3.8 & 1.24 & 15.2 & 23.94 & 190 & $28.98 \mathrm{MJ}$ & 205.2 \\
\hline $10 \%$ PCM & 7.6 & 2.48 & 30.4 & 22.68 & 180 & $32.76 \mathrm{MJ}$ & 210.4 \\
\hline $20 \%$ PCM & 15.2 & 4.95 & 60.8 & 20.16 & 160 & $40.32 \mathrm{MJ}$ & 220.8 \\
\hline $30 \%$ PCM & 22.8 & 7.44 & 91.2 & 17.64 & 140 & $47.88 \mathrm{MJ}$ & 231.2 \\
\hline
\end{tabular}

221

It is clear to see that adding PCM into water tank increases both storage capacity and total mass of the tank. Even $10 \%$ of water is replaced with PCM material, total heat capacity of the tank is increased almost $30 \%$. There is a great potential of capacity improvement; however, heat transfer rates need to be investigated to determine performance improvement. Related heat transfer and energy balance equations are given in modelling section.

\subsection{Controlling supercooled PCMs}

The main objective of the study is to show advantages of using supercooled sodium acetate trihydrate because these PCM modules can release their stored energy when activated by user. Thus, basic control scheme is given in the Fig. 3 to show PCM triggering time, water heating period by PCM, PCM charging period and DHW demand. The UK DHW consumption pattern was measured and identified in a report by Energy Saving Trust [27]. The reference reported that the mean household consumption was 122 litre hot water per day and the average hot water delivery temperature was $51.9^{\circ} \mathrm{C}$. Therefore, Fig 3 is obtained based on this report. However, studies show that even total usage varies from country to country, general hot water usage trend is quite similar for worldwide [28]. Thus, usage trend of the supercooled PCM can be applied into every country with simple capacity optimisations. In Fig. 3, the columns show hourly average water usage by the residents in the UK [27]. Since morning demand reaches the peak level and water tank is cooled down from the night usage, energy consumption for preparing hot water can be maximum in the morning. To compensate this consumption, PCM activation time is settled at $5 \mathrm{am}$. Hot water usage generally starts at 7 am; thus, hot water can be ready for users without any energy consumption because PCMs release the stored heat into water during this period. It is clear that PCM tubes must be recharged, during day time, solar assisted heat pump unit can heat up the water tank in more sustainable way with a better energy efficiency. This heating period can regenerate the PCMs, and at the same time, make hot water ready for the evening demand. Then, water temperature decreases by the evening usage; however, supercooled PCMs still contain stored latent energy for the next morning usage. 


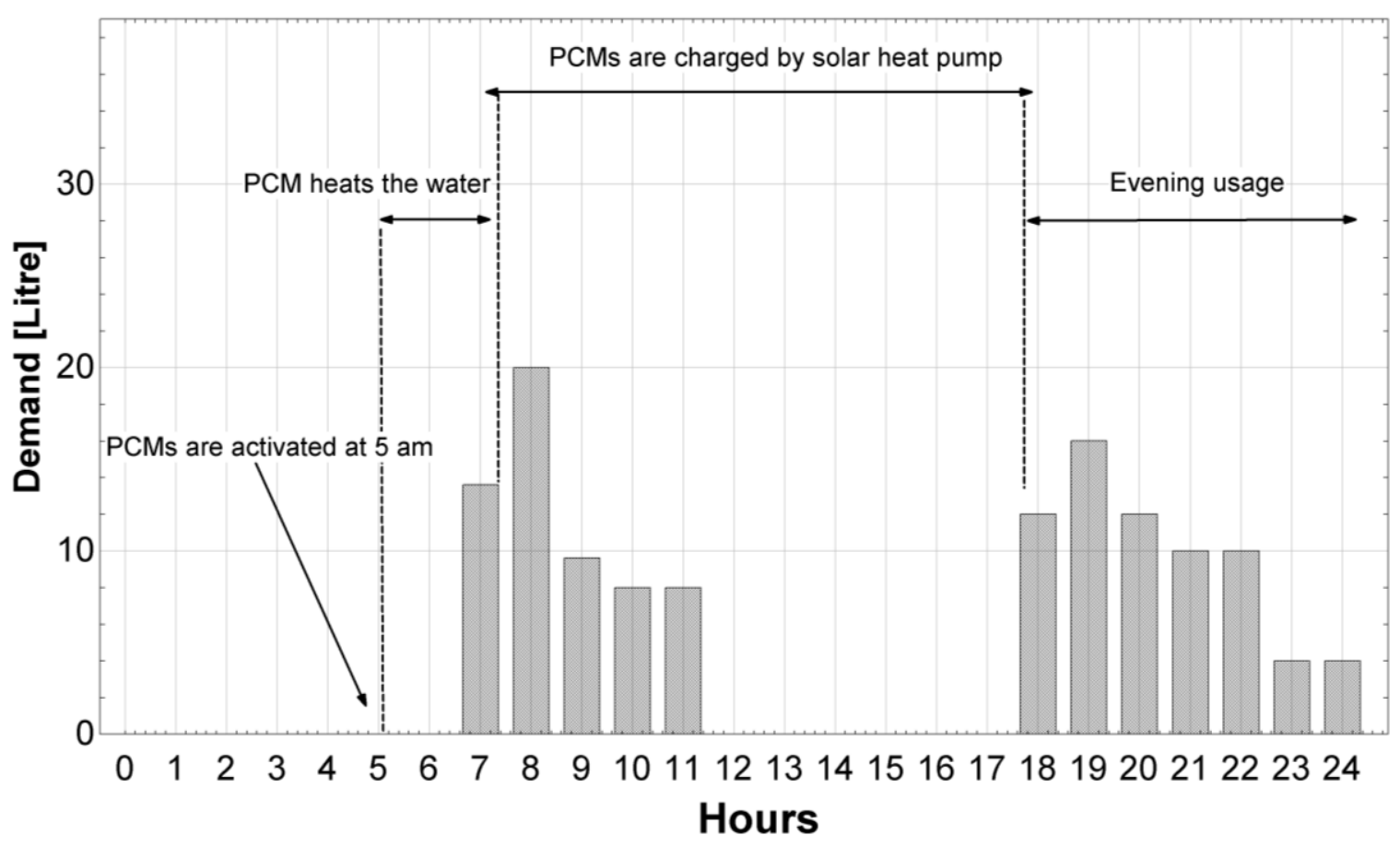

Fig.3. Supercooled PCM control scheme based on time and demand profile

\subsection{Solar collector}

The collector system is modelled as operating under quasi-steady state conditions and used steady state equations, with the thermal capacity of the collectors neglected [29], [30]. Eq. (1) is thermal efficiency equation of the collector.

$$
\eta_{c o l}=\eta_{0}-c_{1} \frac{\bar{T}-T_{a m}}{G}-c_{2} \frac{\left(\bar{T}-T_{a m}\right)^{2}}{G}
$$

Thermomax HP-200 evacuated-tube heat pipe collector [31] is used in the simulations. The modification of the thermal efficiencies under London conditions were taken from Freeman et al. [29]. The zero loss optical efficiency and heat loss coefficients are $\eta_{0}=0.556$, $c_{1}=0.888, c_{2}=0.006$. In order to calculate useful heat and collector outlet temperature, Eq. (2) can be used:

$$
\dot{Q}_{c o l}=\eta_{c o l} \cdot A_{c o l} \cdot G=\dot{m}_{h t f} \cdot c_{p, h t f} \cdot\left(T_{c o l, o u t}-T_{c o l, \text { in }}\right)
$$

\subsection{Heat pump}

Heat pump is commonly used as water source heat pump which is a vapour compression system. It consists of four main components namely; compressor, condenser, expansion valve and evaporator. As this heat pump is a water source heat pump, evaporator is a heat exchanger which transfers the collected heat from the collector into the heat pump. This heat is used as energy source for the heat pump. The following assumptions are considered for heat pump simulation: 
- The evaporation in the evaporator and condensation in the condenser are assumed to be constant pressure process.

- Compressor isentropic efficiency is taken as 0.8 [32].

- The expansion of the refrigerant in the expansion valve is assumed as isenthalpic.

- Superheating in the evaporator and subcooling in the condenser is assumed as $3 \mathrm{~K}$ [33].

- For evaporator, $5 \mathrm{~K}$ pinch temperature difference approach is assumed [33] to ensure proper heat transfer.

According to Eq. (3) and assumptions, refrigerant mass flow rate is determined. As collected heat from the solar collector is used as low temperature heat source, heating capacity of the heat pump depends on the available solar energy.

$$
\dot{Q}_{\text {evaporator }}=\dot{m}_{r} \cdot\left(h_{e+S H}-h_{e}\right)
$$

$\dot{m}_{r}, h_{e}$ and $h_{e+S H}$ indicate refrigerant mass flow rate, evaporator inlet specific enthalpy and evaporator outlet specific enthalpy, respectively. Fig. 4 shows evaporator schematic and pinch temperature difference for the evaporator.
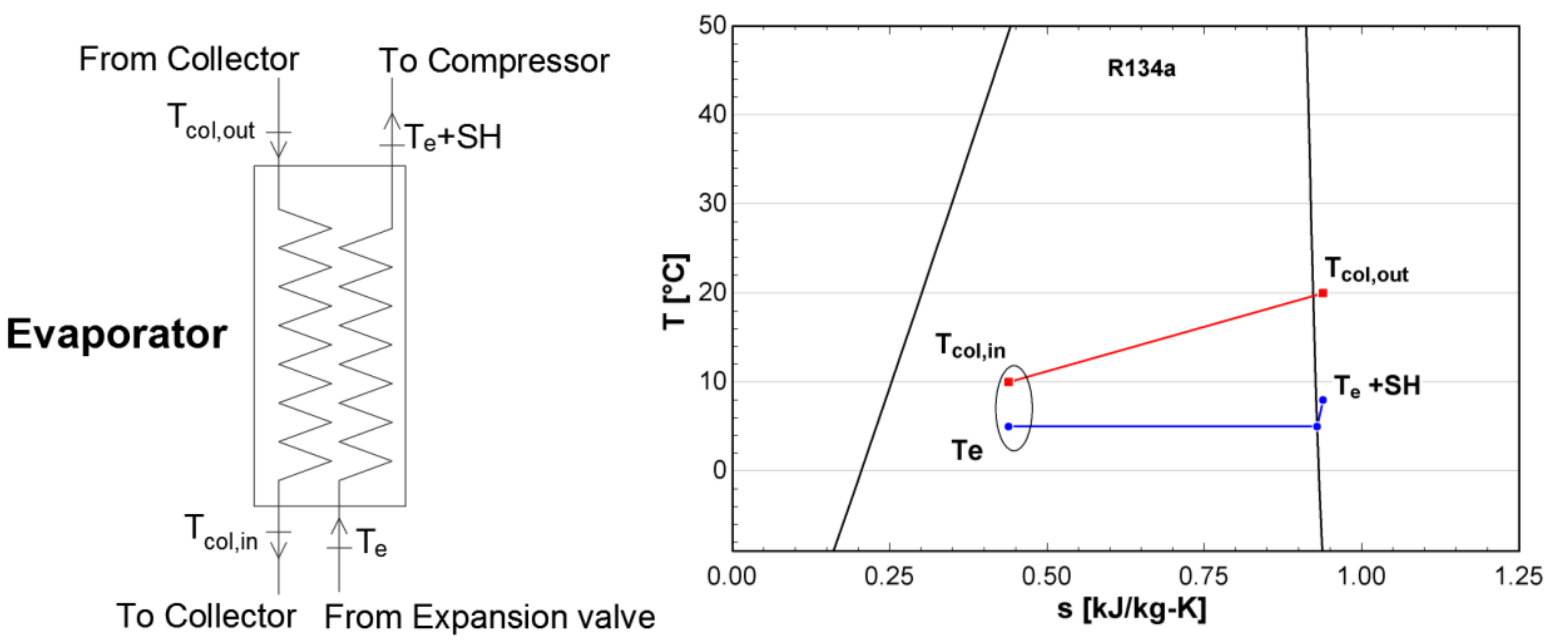

Fig. 4. Evaporator schematic and pinch temperature difference for the evaporator

For condenser modelling, Yerdesh et al. [7] used $7 \mathrm{~K}$ temperature difference to ensure proper heat transfer in both heat exchangers. In this study, difference between condensing temperature of the refrigerant and the water temperature at the top node is selected as $8 \mathrm{~K}$. This conservative approach is chosen to be sure for melting the PCM.

\subsection{Cylindrical water tank}

Multi node water tank simulation has been chosen for modelling the water tank because it allows the system to show potential temperature gradient inside the tank. By this way, PCM tubes are subjected to realistic temperature levels with the water elements. The cylinder volume has been divided into equal volumes to obtain temperature distribution in the storage tank [34]. In every control volume, an energy balance equation can be written considering the 
305

306

307

308

309

310

316

317

318

319

320

321

heat loss to the environment. By solving all the energy balance equations simultaneously, temperature distribution inside the tank can be determined. These methodology have been already used in previous studies [35],[36]. When there is a coil placed in a tank, energy balance equation changes for including its effect and conduction heat transfer between water nodes become more important [37]. The equation is given for a layer in Eq.(4).

$$
T_{t, n}(i+1)=T_{t, n}(i)+\frac{\dot{Q}_{D H W}(i)+\dot{Q}_{c o i l, n}(i)+\dot{Q}_{c o n d, n}(i)+\dot{Q}_{l o s s, n}(i)}{M_{s t, i} \cdot c_{p, w}} \cdot \Delta t
$$

$T_{t, n}$ is tank temperature at node $\mathrm{N} . \mathrm{i}$ and $\mathrm{i}+1$ indicate time steps, $M_{s t, i}$ is the amount of water in each tank element with unit of $\mathrm{kg}, c_{p, w}$ is the specific heat capacity of water.

$\dot{Q}_{D H W}$ indicates drawn heat load by the hot water users because when residents use hot water, same amount of tap water is filled from bottom side of the water tank. Therefore, at each node, the following heat transfer takes place:

$$
\dot{Q}_{D H W}(i)=\dot{m}_{D H W}(i) \cdot c_{p, w}\left(T_{t, n-1}(i)-T_{t, n}(i)\right)
$$

Tap water is charged directly to the last water node in the tank, and water temperature is varying at different time of the year. Although some empirical equations are available in the literature, it will be better to use UK monitored tap water temperatures based on monthly data. The related data is given in Table 3 .

Table 3. UK's monthly cold water temperature variation [38]

\begin{tabular}{|c|c|c|c|}
\hline \multirow{2}{*}{ Month } & \multicolumn{3}{|c|}{ Cold water temperature ${ }^{\circ} \mathrm{C}$} \\
\cline { 2 - 4 } & South England & North England & Scotland \\
\hline January & 12.06 & 9.62 & 9.62 \\
\hline February & 11.33 & 9.32 & 9.15 \\
\hline March & 12.39 & 10.70 & 9.68 \\
\hline April & 15.28 & 13.70 & 13.27 \\
\hline May & 16.14 & 15.32 & 14.49 \\
\hline June & 19.33 & 17.26 & 16.76 \\
\hline July & 21.17 & 19.33 & 19.49 \\
\hline August & 20.09 & 18.67 & 18.44 \\
\hline September & 19.56 & 17.88 & 17.52 \\
\hline October & 16.80 & 15.55 & 15.05 \\
\hline November & 13.70 & 12.22 & 13.73 \\
\hline December & 12.39 & 10.51 & 14.13 \\
\hline
\end{tabular}

It is reported that [37] the most practical approach for heat exchanger design in solar systems is NTU-effectiveness method, each node has coil segment in the tank. In two-coil tank, first coil which is condenser of the heat pump, is placed in top six of the water elements and solar coil only effecting to last four water elements. For heat transfer through coils to the water element, Eq. (6) can be written:

$$
\dot{Q}_{\text {coil }}(i)=\dot{m}_{w}(i) \cdot c_{p} \cdot \varepsilon_{\text {coil }} \cdot\left(T_{\text {coil in }, n}(i)-T_{t, n}(i)\right)
$$


The temperature of the fluid exiting the coil segment in one node, which becomes the temperature entering the next coil segment in the adjacent node. Eq. (7) can be used to calculate temperature outlet:

$$
T_{\text {coil out }, n}(i)=T_{\text {coil in }, n}(i)-\varepsilon_{\text {coil }} \cdot\left(T_{\text {coil in }, n}(i)-T_{t, n}(i)\right)
$$

Conduction heat transfer between water elements is expressed as $Q_{c o n d, n}$ :

$$
\dot{Q}_{c o n d, n}(i)=\frac{\lambda_{e f f} \cdot \pi \cdot D_{t}^{2}}{4 \cdot H_{t, n}} \cdot\left(T_{t, n-1}(i)+T_{t, n-1}(i)-2 \cdot T_{t, n}(i)\right)
$$

$\lambda_{\text {eff }}$ indicates vertical effective thermal conductivity, $H_{t, n}$ and $D_{t}$ are height of the water element and tank diameter, respectively. For $\lambda_{\text {eff }}, 1.85 \mathrm{~W} /(\mathrm{m} / \mathrm{K})$ is used [39].

Regarding to heat loss to the environment, Eq. (9) can be used:

$$
\dot{Q}_{\text {loss }, n}(i)=U_{t} \cdot A_{\text {tank }, n} \cdot\left(T_{\text {room }}-T_{t, n}(i)\right)
$$

Room temperature is assumed as $20^{\circ} \mathrm{C} . A_{\text {tank }, n}$ is heat transfer area of the water tank in one element. It is a surface area between water and the ambient. $U_{t}$ is overall tank heat loss coefficient.

Guarracino et al. [40] summarized the literature assumptions of DHW usage profiles in detail. By considering usage profiles, hourly hot water consumption flow rates and total consumption are determined and modelled. One of the main parameter effecting the thermocline level in the water tank is charging flow rates. Thus, determination of the flow rate is quite important. However, UK monitored data [27] and the given literature data (medium load is $6 \mathrm{l} / \mathrm{min}$ and short load is $3 \mathrm{l} / \mathrm{min}$ ) are not easy to match. In the model, two different flow rates are defined similar to short and medium loads and these loads are used to match with the given total demand profile in Fig.3. The delivery times have been identified according to flow rates considering the $55^{\circ} \mathrm{C}$ delivery temperature such as 6 minutes load with $0.08 \mathrm{~kg} / \mathrm{s}$ at $8 \mathrm{am}$.

\subsection{PCM integrated water tank}

When PCM is placed inside the tank, both sensible and latent heats constitute the total energy of the tank [26] and heat transfer from water to PCM or vice versa is taken into consideration. To analyse temperature gradients with heat transfer process some assumptions have been done.

- The problem is one-dimensional with temperature variations occurs only according to the vertical direction of the tank. Tank height is divided into nodes and each node's energy balance equations are solved simultaneously. 
361

- Some water nodes contain PCM tubes, but these tubes are spaced apart for every element to increase heat transfer area.

- In a water element, water temperature and PCM temperature can be different.

- Each PCM tube is assumed as lumped system.

To increase the heat transfer rate, cylindrical PCM modules (tubes) have been chosen. This selection is also common in the literature studies [10],[11].

Generalized energy equations of PCM has been given by Manfrida et al.[41] in Eq. (10):

$$
V_{P C M} \cdot \rho_{P C M} \cdot L_{P C M} \cdot \frac{\partial \phi}{\partial t}-V_{P C M} \cdot \rho_{P C M} \cdot c_{P C M} \cdot \frac{\partial T}{\partial t}=h_{w-P C M} \cdot A_{w-P C M} \cdot\left(T_{w}-T_{P C M}\right)
$$

$\phi$ is PCM liquid fraction, $h_{w-P C M}$ is heat transfer coefficient between PCM and water element. For the water element, energy balance equation of Eq. (4) needs to be updated as Eq. (11):

$$
T_{t, n}(i+1)=T_{t, n}(i)+\frac{\dot{Q}_{D H W}(i)+\dot{Q}_{c o i l, n}(i)+\dot{Q}_{c o n d, n}(i)+\dot{Q}_{l o s s, n}(i)+\dot{Q}_{w-P C M}(i)}{M_{s t, i} \cdot c_{p, w}} \cdot \Delta t
$$

$\dot{Q}_{w-P C M}(i)$ indicates heat transfer rate between water element and PCM material.

To find the convection heat transfer coefficient, natural convection heat transfer equations for spherical shapes can be valid to use for cylindrical shapes in the water tank [11]. The Nusselt number for natural convection is found by Eq. (12):

$$
N u=\left[0.825+\frac{0.387 \cdot R a^{1.6}}{\left[1+(0.492 / P r)^{9 / 16}\right]^{8 / 27}}\right]^{2}
$$

\subsection{System operation modes}

As given in Fig. 2, the proposed system operates in two modes. Heat pump is active in the first mode and direct solar heating happened in the second mode. To determine these operation modes, temperature of the top node in the water tank has been considered. $70{ }^{\circ} \mathrm{C}$ is chosen in order to avoid legionella, and this temperature is also reasonable for PCM melting. To model operation mode changes in Matlab, a simple control function needs to be used. Followed controlling flow chart is given in Fig. 5. 


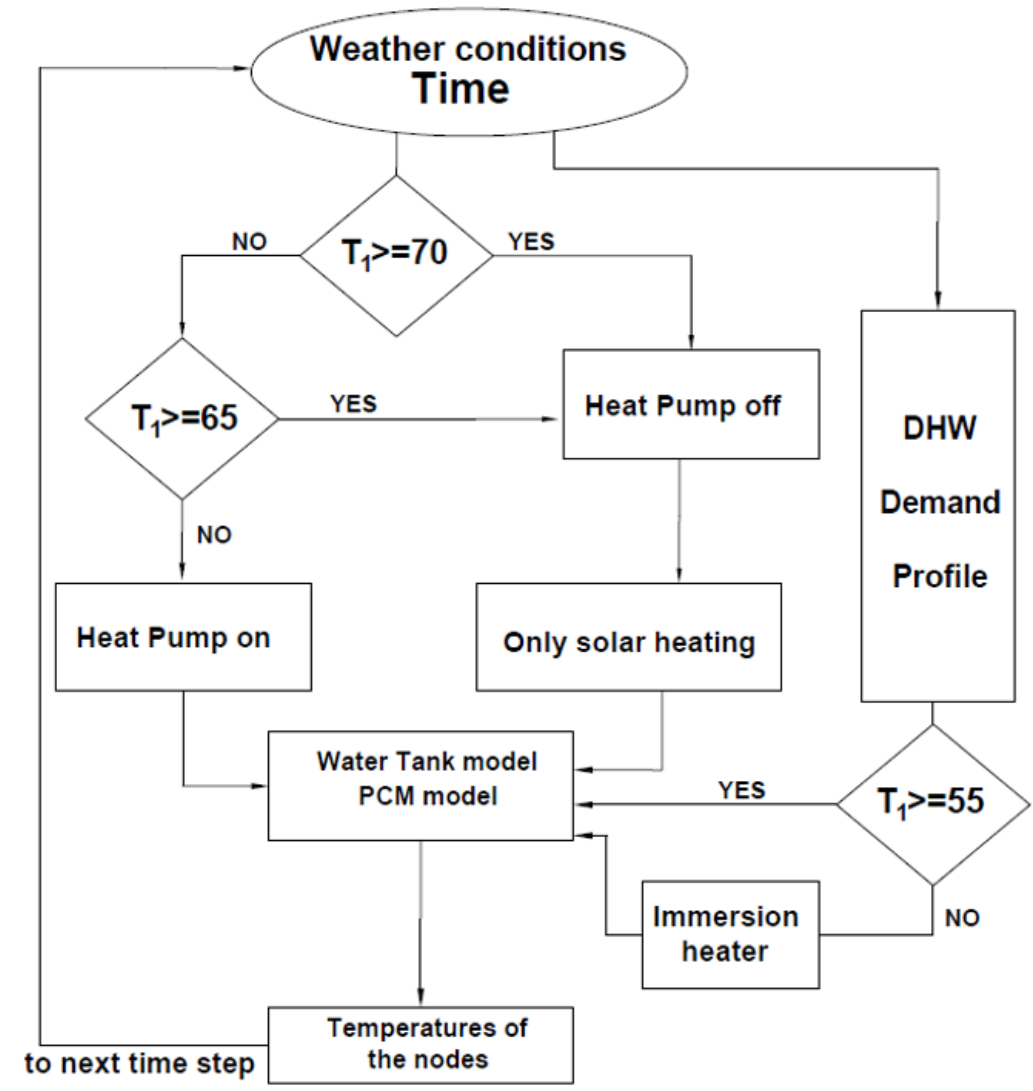

Fig.5. Basic control flowchart of solar assisted heat pump

\section{Results and Discussions}

In the analysis, energy balance equations for all components and heat transfer equations are written in Matlab environment, for refrigerant thermophysical properties, Refprop software is used. In every time step in the model, refrigerant mass flow rate, fluid temperatures and available solar energy are calculated to assess the system performance.

In order to reveal the advantages of the supercooled PCM tubes, a solar assisted heat pump system by using conventional water tank (without PCM) is compared with solar assisted heat pump hot water system with PCM enhanced water tank. Component sizes are kept the same for both systems to observe performance improvement by the PCM addition. Table 4 summarises information about component sizes in the model.

Table 4. Component sizes and simulation information

\begin{tabular}{|c|c|c|c|}
\hline Tank inner diameter & $0.4 \mathrm{~m}$ & Collector area & $4 \mathrm{~m}^{2}$ \\
\hline Tank height & $1.2 \mathrm{~m}$ & Collector flow rate & $0.033 \mathrm{~kg} / \mathrm{s}$ \\
\hline Tank $\mathrm{U}_{\mathrm{T}}$ & $1.5 \mathrm{~W} / \mathrm{m}^{2} \mathrm{~K}$ & $\begin{array}{l}\text { Heat pump working } \\
\text { fluid }\end{array}$ & $\mathrm{R} 134 \mathrm{a}$ \\
\hline $\begin{array}{c}\text { Compressor isentropic } \\
\text { efficiency }\end{array}$ & 0.8 & PCM tube diameter & $40 \mathrm{~mm}$ \\
\hline PCM tube height & $100 \mathrm{~mm}$ & Number of PCM tubes & 116 \\
\hline
\end{tabular}


A detailed analysis has been conducted for a chosen day, for which EnergyPlus weather data [42] is given in Fig. 6. Temperature variation during this day is a typical UK condition but solar irradiance is chosen good solar day as designed condition of the system.

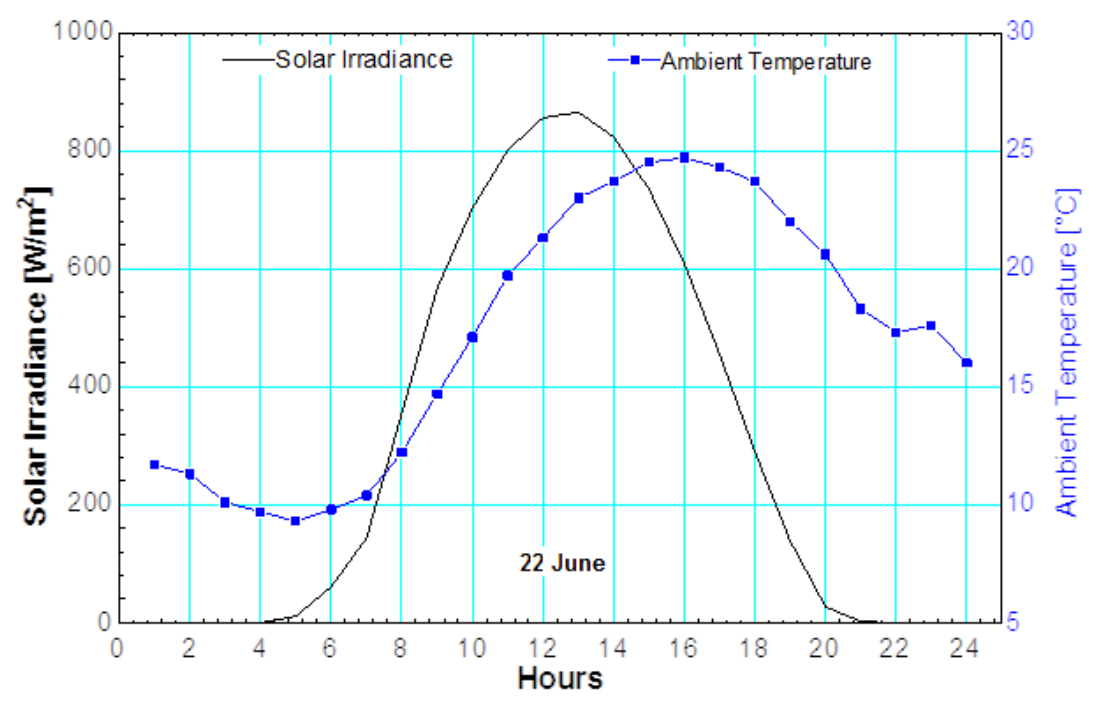

Fig.6. Weather data on 22 June

Hot water delivery temperatures are adjusted to a set temperature of $55^{\circ} \mathrm{C}$. This conservative approach is applied to reveal advantages of using supercooled PCM in the tank. To maintain this temperature when solar heat pump is not active, $2 \mathrm{~kW}$ electrical immersion heater is used in both systems. In the model, initial water element temperatures are determined by solving the mathematical model, the initial temperatures of the water nodes in the tank are the final temperatures of the previous day. However, this study considers only one day, thus, initial temperatures need to be determined. Firstly, an assumed temperature value is given to all water layers and simulation is executed. The final temperatures of the first simulation are used as the initial temperatures of the next simulation. The steps are repeated until the end temperature distribution matches the initial temperature distribution [43].

\subsection{Using a common water tank}

Solar assisted heat pump unit with a conventional water tank has been analysed and results are shown in Fig.7. In Fig. 7a, temperature variation of the top, middle and bottom nodes are shown. The first node is actual delivery temperature to the users and the temperature level is controlled during the day. As it has been mentioned before, the system has two control mechanisms. First one provides desired hot water to the residents when they need it. Set temperature is seen in the Fig.7a as reference line and immersion heater boosts the water temperature if required. As hot water demand starts at $7 \mathrm{am}$, to make hot water ready for the users, the immersion electric heater heats the tank in early morning. When hot water drawn by the users, cold tap water is charged to the tank and temperature of bottom node decreases. Since heat pump has no satisfactory solar heat during early morning and evening, immersion heater provides heat into the tank. 
422

423

424

425

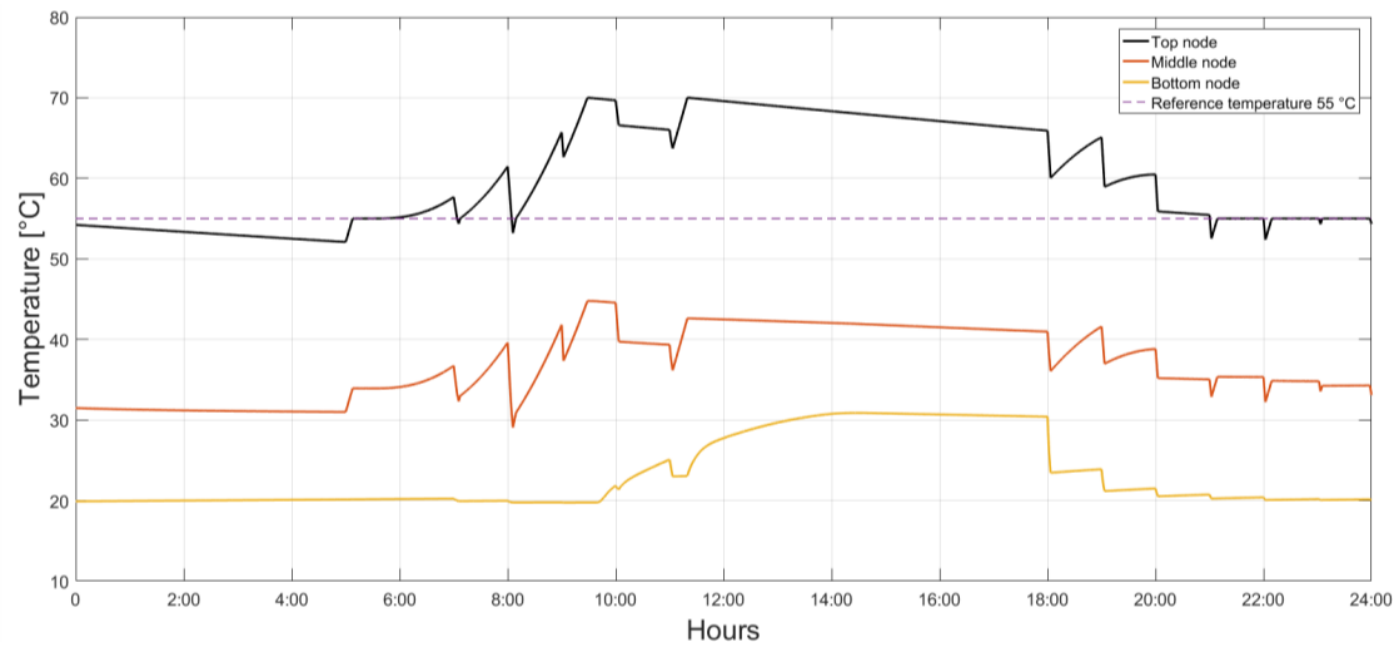

a) Temperature variation in tank during day

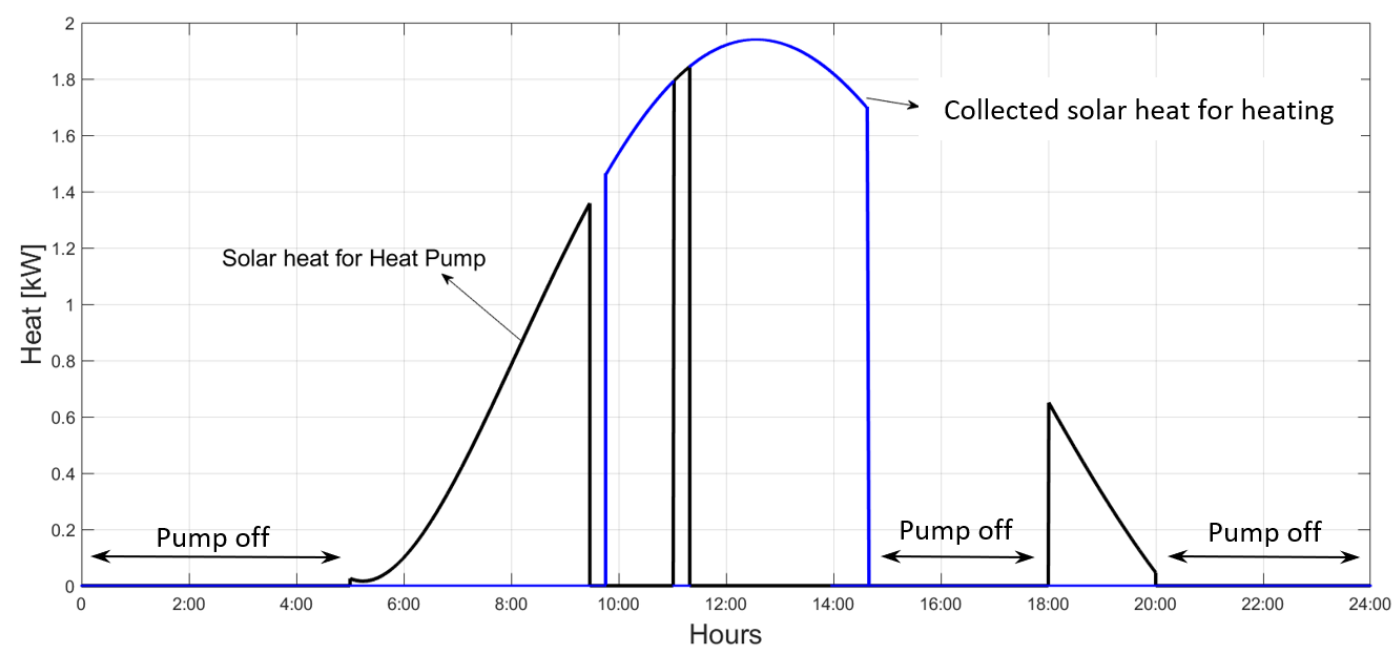

b) Collected solar heat during day

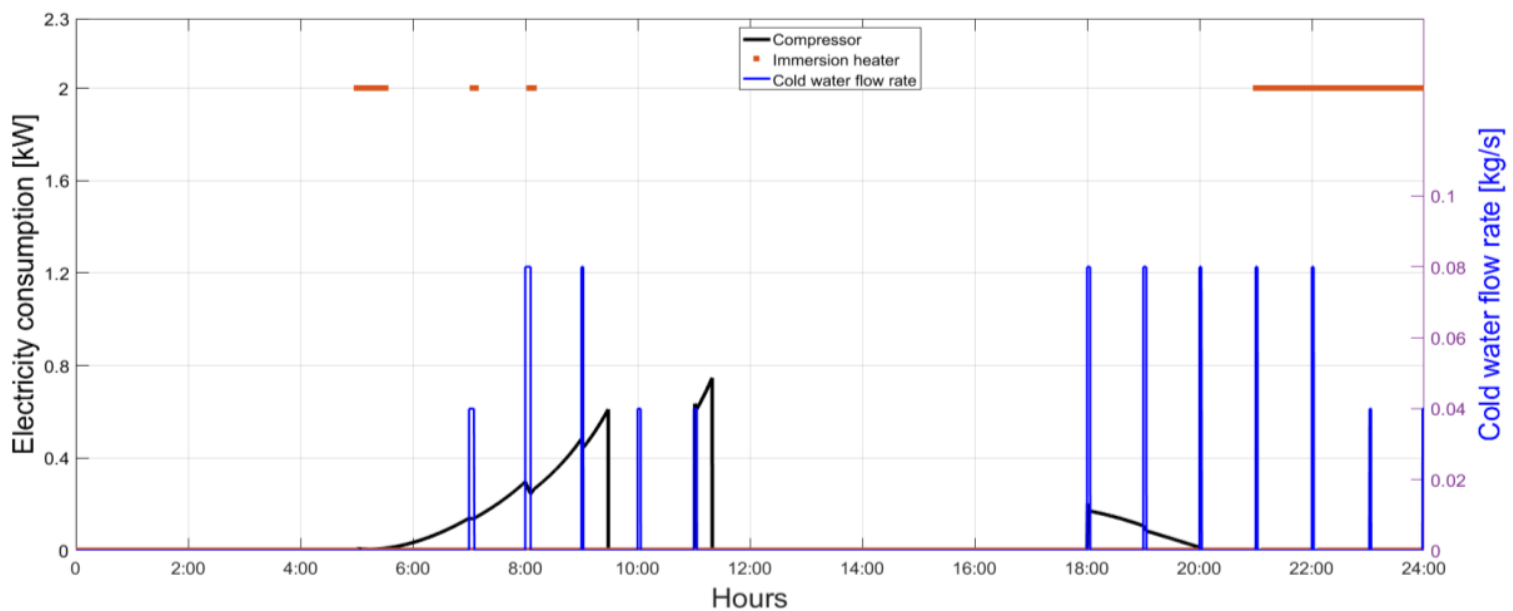

c) Electricity consumption profile

Fig.7. Results for using a common tank in the system. a)Temperature variation in the tank, b)Collected solar heat, c)Electricity consumption 
The second control determines heat pump running times. As it has been explained in methodology, the first node temperature is set to $70^{\circ} \mathrm{C}$. When temperature reaches this set value, it happens at around 9:30 am, the heat pump stops and second control valve is open until the temperature drops to $65^{\circ} \mathrm{C}$. During this period, collector fluid is directly circulated in the lower coil inside the tank. When direct solar heating mode operates, temperatures of the bottom nodes' increase. In order to show collected heat utilization in the system Fig. $7 \mathrm{~b}$ is given. Solar heat is used for heat pump's source and direct heating which depends on system mode of operation. Since DHW demand is high during the morning period, heat pump boots the heating. When system operation switches to the direct solar heating, only consideration is collector outlet temperature must be higher than water tank node. As collector outlet temperature cannot excess node temperature because of heat ejection continues during circulation, collector pump stops to maintain tank temperature.

Fig. 7c shows compressor and immersion heater electricity consumption rates during the day. This figure also gives cold water flow rates by time which defines users' hot water demand profile in right axis. This cold water charges are one of the main reason for electricity consumption. Electric usage by the immersion heater mainly happens during morning and evening periods because heat pump boots temperature in day time. The compressor starts to operate with sun rising and stops at around 9:30 am because the first layer temperature reaches to the set value. However, hot water consumption from the users reduces that temperature under $65^{\circ} \mathrm{C}$ and compressor operates couple of minutes more. When heat pump stops, system operating is changed to direct solar heating mode.

\subsection{Using a PCM integrated water tank}

When PCM tubes are placed in the water tank, simulation with same operating conditions with same parameters are conducted. Fig. 8 shows the results of using PCM enhanced tank in the system. Fig. 8a. shows temperature variation of first, middle and bottom nodes of the water tank. Temperature of the first five nodes increases at 5 am because PCMs are activated and release their stored heat into water. This heat release increases residents' delivery temperature, which can reach higher than the reference temperature; thus, the electric heater is not used during the morning period. In order to prepare PCMs for the next morning, all PCMs must be charged during day. However, heat pump is turned off when water temperature reaches desired level (setting temperature); therefore, immersion heater can help for charging the PCMs. 
465

466

467

468

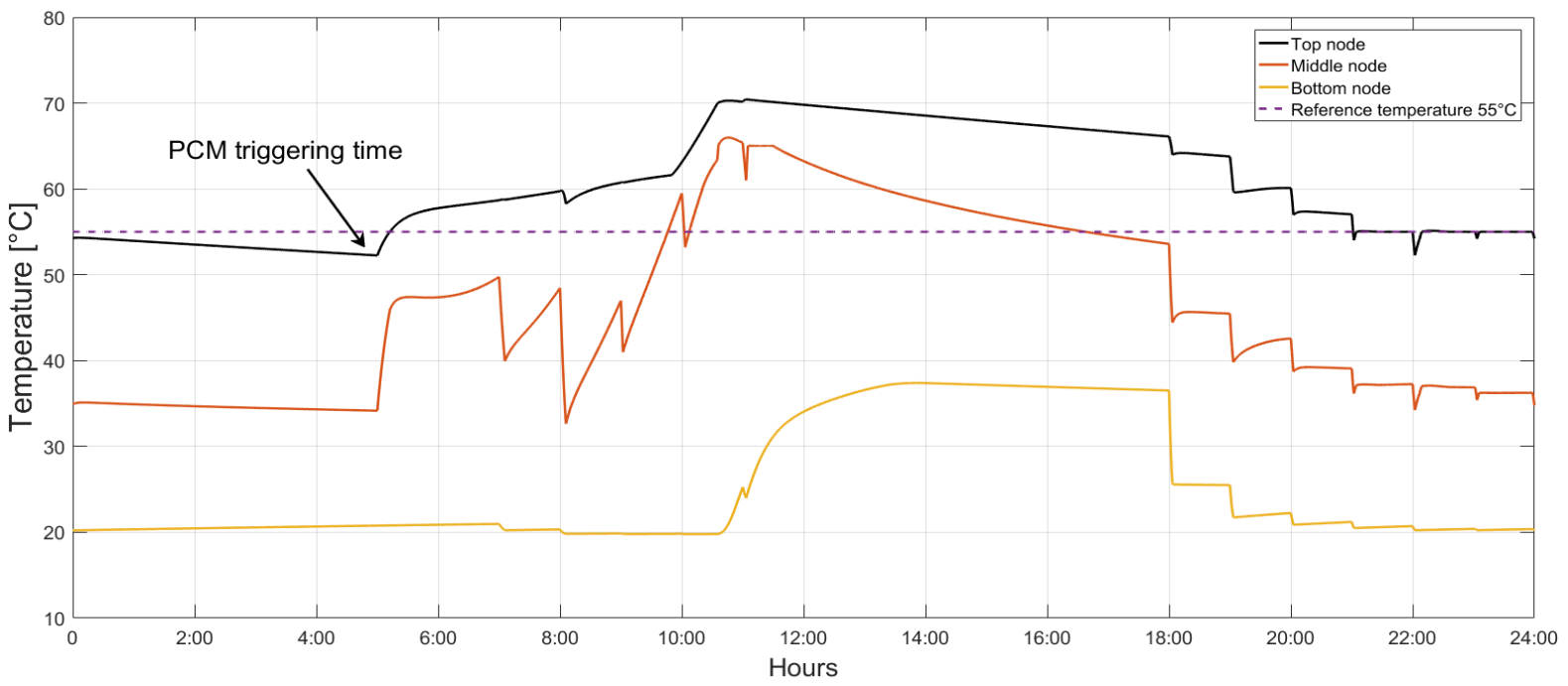

a) Temperature variation in tank during day

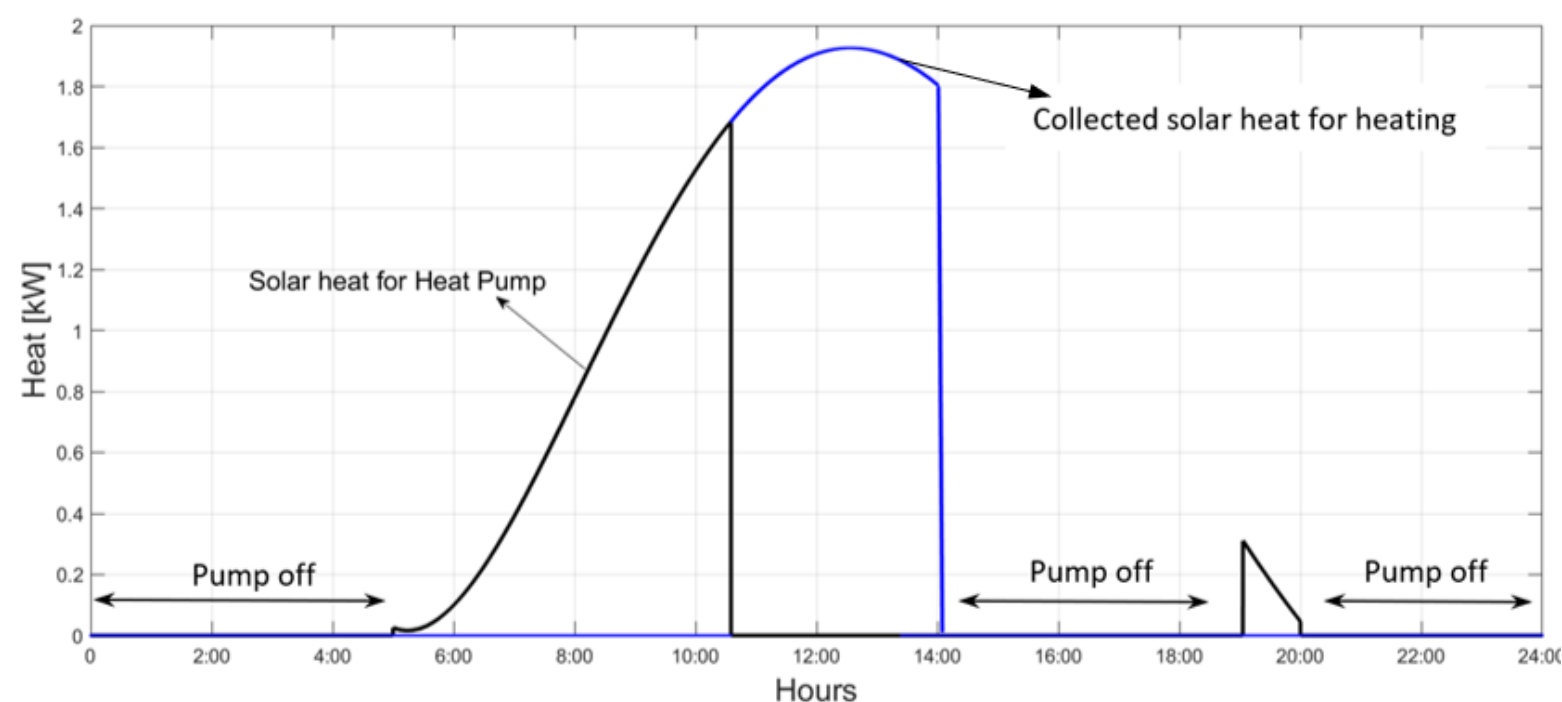

b) Collected solar heat during day

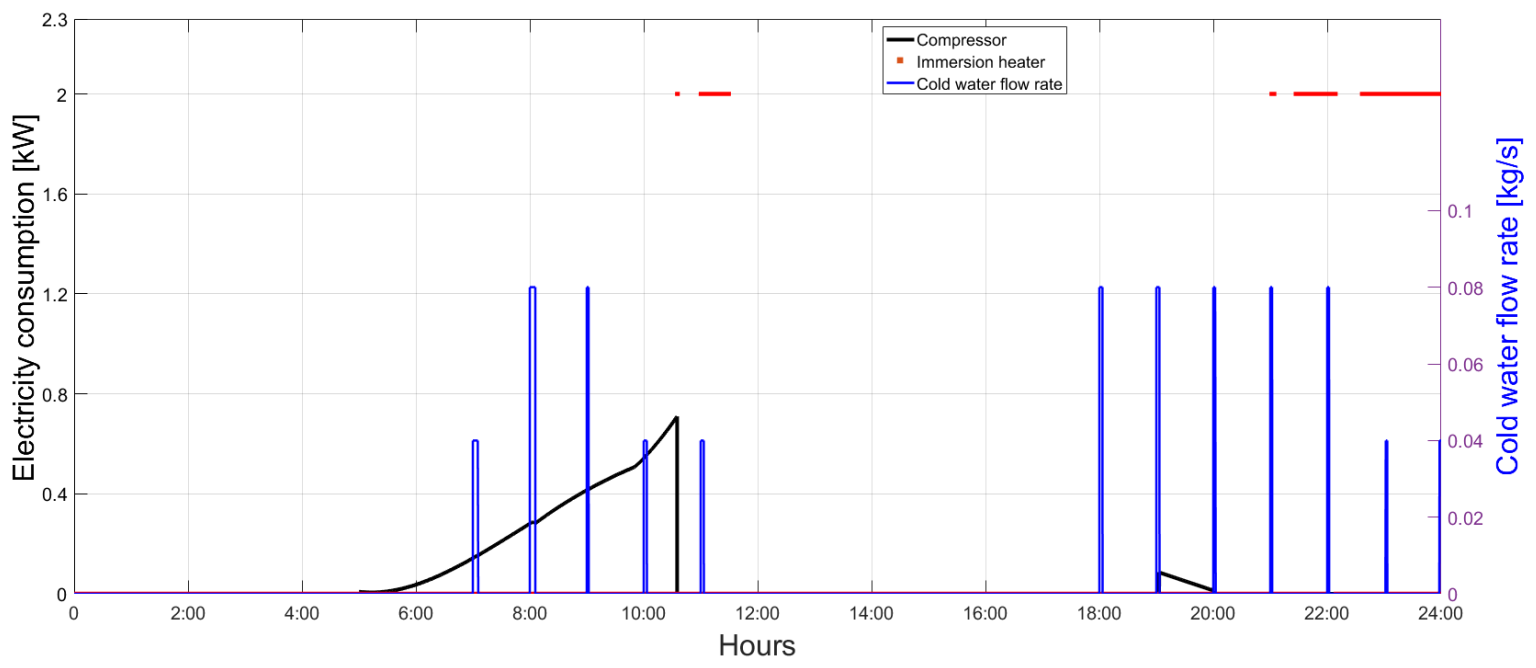

c) Electricity consumption profile 
Fig.8. Results for using a PCM enhanced tank in the system. a)Temperature variation in the tank, b)Collected solar heat, c)Electricity consumption profile

As PCM tubes are placed in the top 5 nodes, releasing their heat creates high stratification inside the cylinder. Thus, direct solar heating mode operates more effectively because bottom layers are colder with respect to the conventional tank. Temperature increment in bottom layers is high as seen in Fig.8a. Collected solar heat is shown in Fig. 8b. Apart from common tanks PCM integrated tank uses more solar heat to drive heat pump because discharged PCM tubes absorb heat and heat pump operates more time to reach set temperature compare to conventional tank system.

Fig. 8c. shows electricity consumption levels and cold water flow rates by time. The heat pump stops at 10:30 am because the first layer reaches to the setting value. However, PCMs are not totally melted especially in the fourth and fifth layers as it can be seen in Fig 9. Therefore, immersion heater is switched on, and it heats up the tank until all PCMs are completely melted. Immersion heater electricity consumption profile is around half an hour in day time. After the sun set, immersion heater is used to maintain reference temperature for residents' hot water usage.

Regarding to the PCM charging and discharging trend, Fig. 9 shows PCM's temperature variations. As hot water rises in the cylinder and cold water is charged from bottom side, placed PCMs in the last two layers exposed to colder temperature. This yields higher heat transfer rate when PCMs are activated and causes quick temperature drop with every cold water charge. However, with help of the immersion heater all PCM tubes are melted at around 11 am. Thus, these melted (charged) PCM tubes can be ready for next day's morning load.

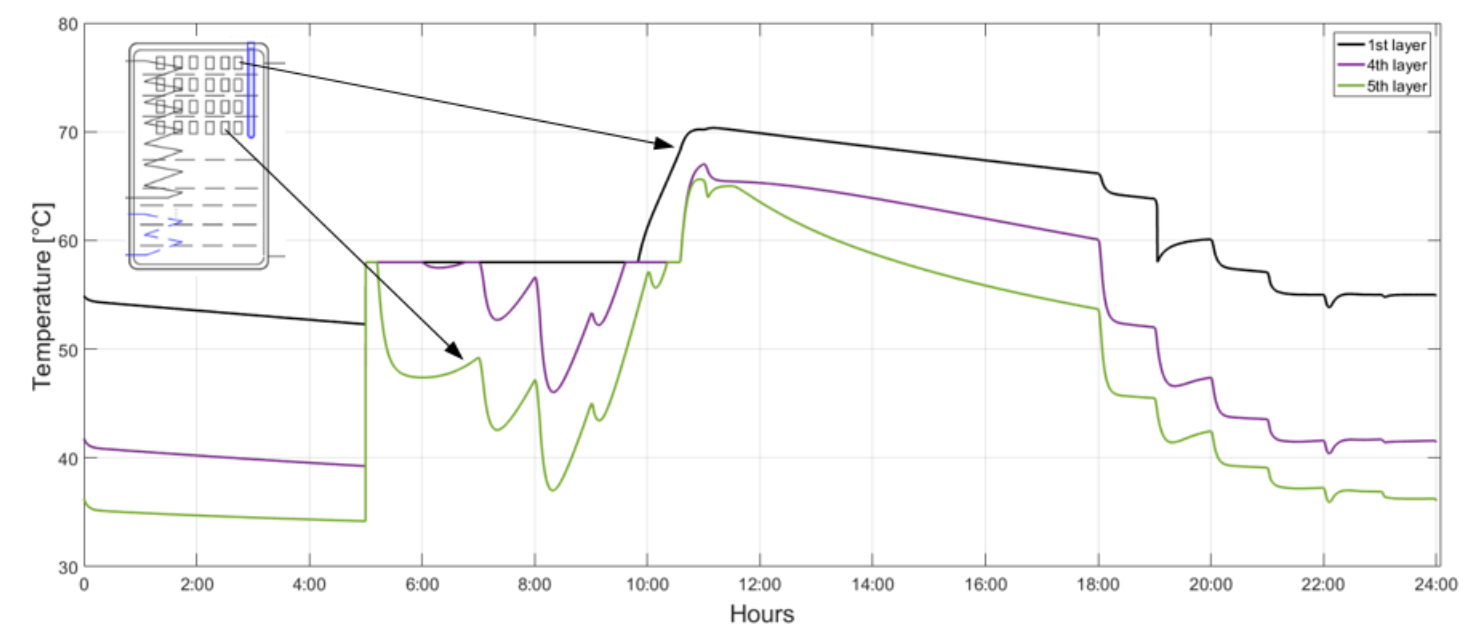

Fig.9. PCM tubes' temperature variation during day

Given figures for comparison of conventional and PCM enhanced tank show that consumption profiles are varied. The main difference is that morning electricity consumption is eliminated by the PCMs. The required energy for the PCMs are compensated by the heat pump and auxiliary immersion heater. It is found that total daily energy consumption is 2.685 $\mathrm{kWh}$ for conventional tank and $2.36 \mathrm{kWh}$ for PCM tank. That means $12.1 \%$ reduction in energy consumption can be achieved by only adding supercooled PCMs in the water tank. This reduction comes from the shifting energy consumption times, there is no electricity 
usage for PCM tank in the morning, but the required energy provided by the heat pump which is more efficient than the immersion heater.

In order to compare heat pump performances, COP variations of both systems is given in Fig. 10. Since both systems' evaporation sides are exposed to same condition, difference comes from the condensing temperatures. The main difference is PCM integrated system's COP is more stable because PCM tubes absorb heat during heating period, this limits the temperature increment of the first node, and thus, condensing temperature remains stable. In contrast, conventional tank temperature easily increases by the heating and decrease by the cold water charging. Conventional tank system's COP reduces after 8:45 am because of temperature increment, however, PCM integrated tank system's COP decreases around $10 \mathrm{am}$. The reason can be explained that PCMs are melted in the top layers and allows to increase of the water temperature.

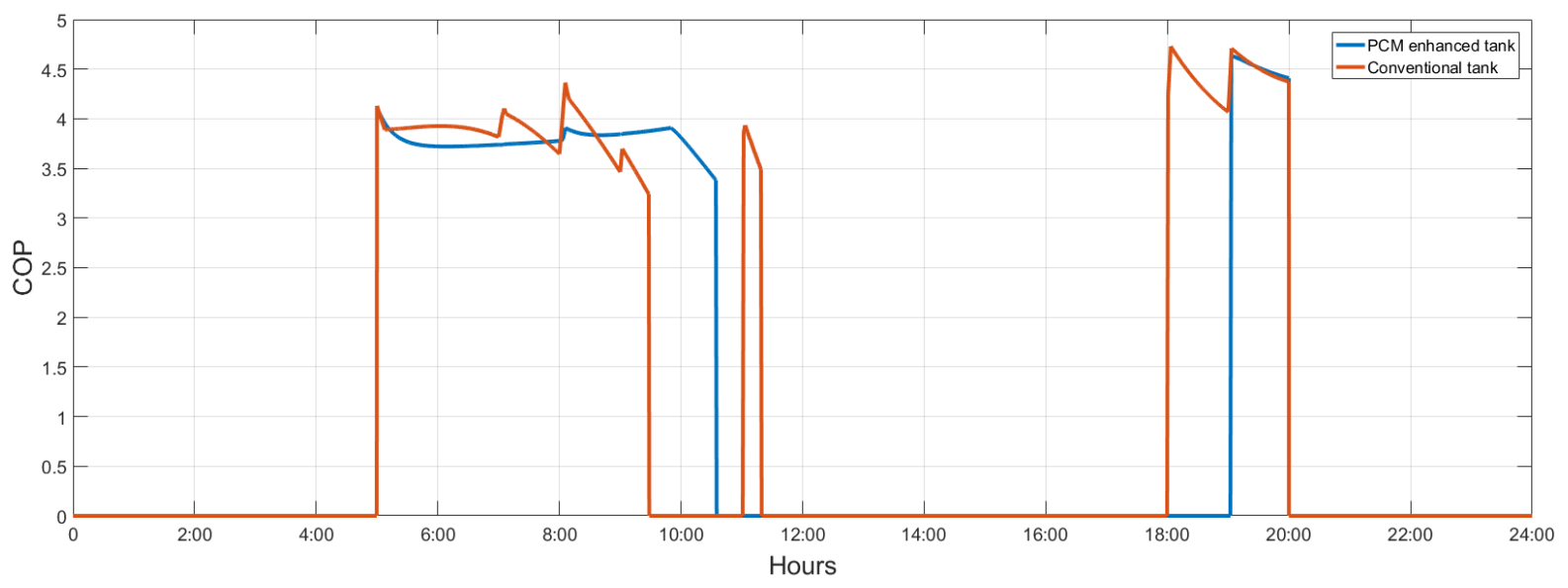

Fig. 10. COP variations of both systems

In order to show advantages of PCM enhancement in the SAHP unit, another analysis is conducted by using different weather conditions. The simulation given above is a good example of good solar radiation condition in the UK but another simulation is conducted for testing the system under the average solar radiation. $8^{\text {th }}$ of April is chosen for next simulation because solar radiation reaches maximum $560 \mathrm{~W} / \mathrm{m}^{2}$ and tap water temperature is around 15 ${ }^{\circ} \mathrm{C}$. It is found that total daily energy consumption increased to $3.89 \mathrm{kWh}$ for conventional tank and $3.367 \mathrm{kWh}$ for PCM enhanced tank. Since low temperature tap water charging and weaker solar radiation, this higher consumption is expected. Compressor consumptions are increased because water tank needs more heat to reach reference set temperature. This result shows that PCM enhancement can achieve $13.4 \%$ reduction of energy consumption in DHW system even under average weather conditions. Table 5 summaries consumptions of both systems for summer and spring days. $0.325 \mathrm{kWh}$ of reduction in electricity consumption is achieved in a summer day and $0.523 \mathrm{kWh}$ of reduction in electricity consumption is achieved in a spring day. This result proves that more solar heat can be utilized by the heat pump when solar radiation is lower. Shifting the heating process from immersion heater to solar heat pump results more promising in low radiation days when direct solar heating is not enough for DHW applications.

Table 5. Summary of energy consumptions 


\begin{tabular}{|c|c|c|c|}
\hline & \multicolumn{3}{|c|}{ Consumptions-kWh } \\
\hline & Immersion heater & Compressor & Total \\
\hline Conventional tank in June & 1.39 & 1.295 & 2.685 \\
\hline PCM enhanced tank in June & 0.86 & 1.5 & 2.36 \\
\hline Conventional tank in April & 2.454 & 1.44 & 3.89 \\
\hline PCM enhanced tank in April & 1.586 & 1.78 & 3.367 \\
\hline
\end{tabular}

539

540

541

542

543

544

545

546

547

548

549

550

551

552

553

554

555

556

557

558

559

560

561

562

563

564

565

566

567

568

569

570

571

572

573

574

\section{Conclusion}

In this study, a solar assisted heat pump system for DHW applications has been modelled. Solar collectors, heat pump, water tank and DHW demand have been transiently modelled using Matlab. Although PCM increases the heat capacity of the water tank, this study focuses on reduction of the electricity consumption rates for a 24 hour period. The performance of conventional and PCM integrated tanks have been compared. Using control methodologies, temperature variations in the water tank, collected solar heat and electricity consumption profiles have been obtained and discussed. Results show that the proposed novel control method of the supercooled PCMs can provide required heat for the morning hot water demand and it can reduce daily DHW energy consumption by about $12.1-13.4 \%$ according to weather conditions. Since the main benefit of using supercooled PCMs in the system is shifting heating energy from immersion heater to the heat pump, proposed system also improves the renewable energy utilisation. It is also cost effective system because advantages can be achieved by only adding PCM tubes to an existing SAHP DHW system.

\section{Acknowledgements}

The authors would like to acknowledge the financial support and contributions from Innovate UK (project code: 104311) and thank our project partners PCMP Ltd, Geo Green Power Ltd, Midea and SCUT for supporting this project.

\section{References}

[1] J. Prime, CHP 1: Overall Data Tables, Energy Consumption in the UK, 2014.

[2] Next steps for UK heat policy Committee on Climate Change, (2016). https://www.theccc.org.uk/wp-content/uploads/2016/10/Next-steps-for-UK-heatpolicy-Committee-on-Climate-Change-October-2016.pdf (accessed December 5, 2019).

[3] E. Bellos, C. Tzivanidis, K. Moschos, K.A. Antonopoulos, Energetic and financial evaluation of solar assisted heat pump space heating systems, Energy Convers. Manag. 120 (2016) 306-319. https://doi.org/10.1016/j.enconman.2016.05.004.

[4] J. Cai, Z. Li, J. Ji, F. Zhou, Performance analysis of a novel air source hybrid solar assisted heat pump, Renew. Energy. 139 (2019) 1133-1145. https://doi.org/10.1016/j.renene.2019.02.134.

[5] X. Wang, L. Xia, C. Bales, X. Zhang, B. Copertaro, A systematic review of recent air source heat pump ( ASHP) systems assisted by solar thermal, photovoltaic and photovoltaic / thermal sources, Renew. Energy. 146 (2020) 2472-2487.

https://doi.org/10.1016/j.renene.2019.08.096. 
[6] X. Kong, P. Sun, Y. Li, K. Jiang, S. Dong, Experimental studies of a variable capacity direct-expansion solar-assisted heat pump water heater in autumn and winter conditions, Sol. Energy. 170 (2018) 352-357. https://doi.org/10.1016/j.solener.2018.05.081.

[7] Y. Yerdesh, Z. Abdulina, A. Aliuly, Y. Belyayev, M. Mohanraj, A. Kaltayev, Numerical simulation on solar collector and cascade heat pump combi water heating systems in Kazakhstan climates, Renew. Energy. 145 (2020) 1222-1234. https://doi.org/10.1016/j.renene.2019.06.102.

[8] H. Mehling, L.F. Cabeza, S. Hippeli, S. Hiebler, PCM-module to improve hot water heat stores with stratification, Renew. Energy. 28 (2003) 699-711.

[9] E. Talmatsky, A. Kribus, PCM storage for solar DHW: An unfulfilled promise?, Sol. Energy. 82 (2008) 861-869. https://doi.org/10.1016/j.solener.2008.04.003.

[10] T. Kousksou, P. Bruel, G. Cherreau, V. Leoussoff, T. El Rhafiki, PCM storage for solar DHW: From an unfulfilled promise to a real benefit, Sol. Energy. 85 (2011) 2033-2040. https://doi.org/10.1016/j.solener.2011.05.012.

[11] R. Padovan, M. Manzan, Genetic optimization of a PCM enhanced storage tank for Solar Domestic Hot Water Systems, Sol. Energy. 103 (2014) 563-573. https://doi.org/10.1016/j.solener.2013.12.034.

[12] G.S. Kumar, D. Nagarajan, L.A. Chidambaram, V. Kumaresan, Y. Ding, R. Velraj, Role of PCM addition on strati fi cation behaviour in a thermal storage tank e An experimental study, Energy. 115 (2016) 1168-1178. https://doi.org/10.1016/j.energy.2016.09.014.

[13] M. Shirinbakhsh, N. Mirkhani, B. Sajadi, A comprehensive study on the effect of hot water demand and PCM integration on the performance of SDHW system, Sol. Energy. 159 (2018) 405-414. https://doi.org/10.1016/j.solener.2017.11.008.

[14] G. Coquerel, Crystallization of molecular systems from solution: phase diagrams, supersaturation and other basic concepts, Chem Soc Rev. (2014) 2286-2300. https://doi.org/10.1039/c3cs60359h.

[15] E. Garskaite, K. Gross, S. Yang, T.C. Yang, J. Yang, A. Kareiva, Effect of processing conditions on the crystallinity and structure of carbonated calcium hydroxyapatite (CHAp), Cryst Eng Comm. (2014) 3950-3959. https://doi.org/10.1039/c4ce00119b.

[16] O.D. Linnikov, Mechanism of precipitate formation during spontaneous crystallization from supersaturated aqueous solutions, Russ. Chem. Rev. (2014). https://doi.org/10.1070/RC2014v083n04ABEH004399.

[17] R.J. Davey, R.J. Davey, S.L.M. Schroeder, J.H. Horst, Nucleation of Organic Crystals - A Molecular Perspective Angewandte, Angew. Rev. (2013) 2166-2179. https://doi.org/10.1002/anie.201204824.

[18] S. Canbazoglu, S. Abdulmuttalip, A. Ekmekyapar, G. Aksoy, F. Akarsu, Enhancement of solar thermal energy storage performance using sodium thiosulfate pentahydrate of a conventional solar water-heating system, Energy Build. 37 (2005) 235-242. https://doi.org/10.1016/j.enbuild.2004.06.016.

[19] H. Mohammadzadeh-aghdash, Y. Sohrabi, A. Mohammadi, Safety assessment of sodium acetate, sodium diacetate and potassium sorbate food additives, Food Chem. 
[20] C. JC, S. DA, A. JD, Patterned self-warming wipe substrates, 2011. https://patents.google.com/patent/WO2010001294A3/en.

[21] L. Wei, K. Ohsasa, Supercooling and Solidification Behavior of Phase Change, ISIJ Int. 50 (2010) 1265-1269.

[22] N. Beaupere, U. Soupremanien, L. Zalewski, Thermochimica Acta Nucleation triggering methods in supercooled phase change materials ( PCM ), a review, Thermochim. Acta. 670 (2018) 184-201. https://doi.org/10.1016/j.tca.2018.10.009.

[23] B. Sandnes, The physics and the chemistry of the heat pad, Am. J. Phys. 76 (2008) 546-550. https://doi.org/10.1119/1.2830533.

[24] M.C. Rodríguez-Hidalgo, P.A. Rodríguez-Aumente, A. Lecuona, M. Legrand, R. Ventas, Domestic hot water consumption vs. solar thermal energy storage: The optimum size of the storage tank, Appl. Energy. 97 (2012) 897-906. https://doi.org/10.1016/j.apenergy.2011.12.088.

[25] Z. Ma, H. Bao, A.P. Roskilly, Study on solidification process of sodium acetate trihydrate for seasonal solar thermal energy storage, Sol. Energy Mater. Sol. Cells. 172 (2017) 99-107. https://doi.org/10.1016/j.solmat.2017.07.024.

[26] H. Huang, Z. Wang, H. Zhang, B. Dou, X. Huang, H. Liang, M.A. Goula, An experimental investigation on thermal stratification characteristics with PCMs in solar water tank, Sol. Energy. 177 (2019) 8-21. https://doi.org/10.1016/j.solener.2018.11.004.

[27] Defra Report, Measurement of domestic hot water consumption in dwellings, Defra Rep. (2008) 1-62.

https://www.gov.uk/government/uploads/system/uploads/attachment_data/file/48188/3 147-measure-domestic-hot-water-consump.pdf (accessed December 5, 2019).

[28] E. Fuentes, L. Arce, J. Salom, A review of domestic hot water consumption profiles for application in systems and buildings energy performance analysis, Renew. Sustain. Energy Rev. 81 (2018) 1530-1547. https://doi.org/10.1016/j.rser.2017.05.229.

[29] J. Freeman, I. Guarracino, S.A. Kalogirou, C.N. Markides, A small-scale solar organic Rankine cycle combined heat and power system with integrated thermal energy storage, Appl. Therm. Eng. 127 (2017) 1543-1554. https://doi.org/10.1016/j.applthermaleng.2017.07.163.

[30] C. Kutlu, J. Li, Y. Su, Y. Wang, G. Pei, S. Riffat, Annual performance simulation of a solar cogeneration plant with sensible heat storage to provide electricity demand for a small community: A transient model, Hittite J. Sci. Eng. 6 (2019) 75-81. https://doi.org/10.17350/HJSE19030000125.

[31] Kingspan, Direct Flow Vacuum Tube Solar Collector, (2017).

[32] T. Yilmaz, M.T. Erdinç, Energetic and exergetic investigation of a novel refrigeration system utilizing ejector integrated subcooling using different refrigerants, Energy. 168 (2019) 712-727. https://doi.org/10.1016/j.energy.2018.11.081.

[33] G.F. Hundy, Refrigeration, Air Conditioning and Heat Pumps, 5th ed., ButterworthHeinemann, 2016. 
[34] J.A. Duffie, W.A. Beckman, Solar Engineering of Thermal Processes, John Wiley, 2013.

[35] E. Bellos, C. Tzivanidis, K. Moschos, K.A. Antonopoulos, Energetic and financial evaluation of solar assisted heat pump space heating systems, Energy Convers. Manag. 120 (2016) 306-319. https://doi.org/10.1016/j.enconman.2016.05.004.

[36] C. Kutlu, M. Tahir, J. Li, Y. Wang, Y. Su, A study on heat storage sizing and fl ow control for a domestic scale solar-powered organic Rankine cycle-vapour compression refrigeration system, Renew. Energy. 143 (2019) 301-312. https://doi.org/10.1016/j.renene.2019.05.017.

[37] M. Herrando, A. Ramos, J. Freeman, I. Zabalza, C.N. Markides, Technoeconomic modelling and optimisation of solar combined heat and power systems based on flatbox PVT collectors for domestic applications, Energy Convers. Manag. 175 (2018) 67-85. https://doi.org/10.1016/j.enconman.2018.07.045.

[38] Z. Ma, H. Bao, A.P. Roskilly, Feasibility study of seasonal solar thermal energy storage in domestic dwellings in the UK, Sol. Energy. 162 (2018) 489-499. https://doi.org/10.1016/j.solener.2018.01.013.

[39] M. Herrando, C.N. Markides, K. Hellgardt, A UK-based assessment of hybrid PV and solar-thermal systems for domestic heating and power: System performance, Appl. Energy. 122 (2014) 288-309. https://doi.org/10.1016/j.apenergy.2014.01.061.

[40] I. Guarracino, A. Mellor, N.J. Ekins-Daukes, C.N. Markides, Dynamic coupled thermal-and-electrical modelling of sheet-and-tube hybrid photovoltaic/thermal (PVT) collectors, Appl. Therm. Eng. 101 (2016) 778-795. https://doi.org/10.1016/j.applthermaleng.2016.02.056.

[41] G. Manfrida, R. Secchi, K. Stańczyk, Modelling and simulation of phase change material latent heat storages applied to a solar-powered Organic Rankine Cycle, Appl. Energy. 179 (2016) 378-388. https://doi.org/10.1016/j.apenergy.2016.06.135.

[42] D.B. Crawley, L.K. Lawrie, U.S. Army, C. Champaign, I. Curtis, O. Pedersen, F.C. Winkelmann, EnergyPlus: Energy Simulation Program, ASHRAE J. 42 (2000) 49-56. https://doi.org/10.1.1.122.6852.

[43] C. Kutlu, J. Li, Y. Su, G. Pei, S. Riffat, Off-design performance modelling of a solar organic Rankine cycle integrated with pressurized hot water storage unit for community level application, Energy Convers. Manag. 166 (2018) 132-145. https://doi.org/10.1016/j.enconman.2018.04.024. 


\section{Author contributions}

Manuscript title: A Simulation Study on Performance Improvement of Solar Assisted Heat Pump Hot Water System by Novel Controllable Crystallisation of Supercooled PCMs

Cagri Kutlu: Investigation, modelling, writing

Yanan Zhang: Investigation, writing

Theo Elmer: Review and editing

Yuehong Su: Methodology, review and editing

Saffa Riffat: Investigation, supervision 